\title{
Mental Health: Promoting Awareness Through 3D Animated Short Film
}

\author{
Dahlan Abdul Ghani, Nur Adila Binti Muhd Affendy
}

\begin{abstract}
Having a mental health problem quite upsetting, confusing and scary at first. The scares often be filled with negative thoughts that can be unrealistic way to happen just like been shown on the media. Mental health is a common human experience, but by having the mental illness is something that needs the treatment. Some of people living in current times causing depression, anxiety and many others of mental health problems. Some young working adults struggle with emotional and physical issues as they leave university, before or maybe in working world. The aim of the research is to study about the mental health issues among the animators or artists in creative industry and it will be focus on the visualising the issues arise in animation in certain medium which is in 3D (3-Dimensional) animation. With this research, we hoped that it will increase the knowledge to people about mental illness that been faced by the animators and can create the awareness regarding mental health issues through the animation.
\end{abstract}

Keywords: mental illness, 3D animation, awareness, mental health, depression, animators, pixar, body movement, colour.

\section{INTRODUCTION}

Mental health is a level of a psychological of an absence of the mental illness. It is a result of the chemical reactions in the brain. It can be the emotions, thoughts and feelings to have the strength in facing the problems and difficulties. While mental illness is an illness that not everyone feels, it can affect how people think, feel or behaviour towards others and it conclude in many different mental illnesses in how they live differently.

This research will be focus on the mental health issues. Due to lack of awareness on the validity behind mental health issues, there is a tendency for mental illness to be chalked down as something that went wrong with the people who dare to share about their struggles in animations. The mental illness not only happened to normal people but also experience it to famous artist and animators out there. article in 2018, she said that animations have the power to tell the health to inspire people. Many people also finds the arts and animations can visualising the situation of the mental illness itself to other people who not being exposed about this mental health issues that arise.

Based on interview of Panagioti Karagianni to Alex Widdowson an animator who created the animated documentary "Patients" in 2016 regarding the question of Patients and his latest reworking of the project are a great presentation of a very big issue of society: mental illness.

Revised Manuscript Received on September 10, 2019.

Dahlan Abdul Ghani, Universiti Kuala Lumpur, Malaysian Institute of Information Technology, Jalan Sultan Ismail, Kuala Lumpur, Malaysia. (Email: adilaaffendy@gmail.com)

Nur Adila Binti Muhd Affendy, Universiti Kuala Lumpur, Malaysian Institute of Information Technology, Jalan Sultan Ismail, Kuala Lumpur, Malaysia. (Email: dahlan@unikl.edu.my) According to Sarah Wishart, Rights Info Creative Director

What did inspire him to occupy with an edgy and so alive with the issue?

"It's nice that not everyone assumes that these films are biographical. They most definitely are, but still it's comforting that sometimes people assume they're no more than an artistic and journalistic endeavour. The truth is that they are painfully close to my heart. Part of the value these films is that when I look back at my most difficult experiences, those traumatic images have now been substituted by my drawings. This pain has been so heavily processed I often perceive the scenes I've made in my films rather than a direct memory. I feel very blessed that I can use art in this way. Mental illness is a very tangible and pervasive phantom in all our lives. If you have never been affected directly you may at least know someone who has, yet until recently in Britain there was a strong convention not to talk openly about this topic. Charities like Mind and Time To Change had genuinely shaped the landscape when it comes to stigma. I hope my films made a modest contribution"

Based on what the animator said, we see the animation can visualize about the mental health because it has a strong and can openly to talk about what is inside the head of those who have the mental illness.

The visualising about mental health awareness through animation has been made through the original research about the mental illness in Disney animated films by Andrea Lawson and Gregory Fouts in 2004. They stated, The Walt Disney Company (TWDC) already produced the animated films feature films between years 1937 until 2001. Almost $85 \%$ of their animated films the characters with mental illness for example like Maurice from Beauty and The Beast, Jaafar of Aladdin and Mrs Jumbo of Dumbo. This might not been see by other people but them already aware about the mental illness since 90 to be put in the animation. But the focus is too low at that time. They said, the children who watch animated films of The Walt Disney Company are exposed to have an increasing of having a mental illness than they need to experience in their everyday lives. Thus, people already watching Disney movies that have not been reconsidering as the characters who mentally ill.

Mental illness that used to highlight is depression. It is shown basically in television and film to portray the character's life for example in Netflix series an American adult animated comedy-drama, BoJack Horseman by Raphael Bob-Waksberg's. The series is about the horse character in the animation suffered from depression.

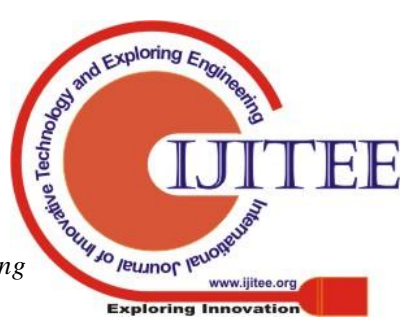


The way the character's been put in the horse character about the mental illness conclude all the vision for those who suffered and how they feel.

\section{LITERATURE REVIEWS}

\subsection{The overview based on mental health issues}

The number of American adults having mental illness more than the populations over 40 million Americans of the New York and Florida combined (Mental Health America, 2015). It showed that, these days, in 2018, many people having a mental breakdown and almost many of them did not receive the treatment. Mental health issues not only arise among the normal people but also encounters among the animators. Some of them visualise the mental health issue mostly through their own animation and illustration. This topic will be covering the review on visualising the mental health issue in 3D animation. The effectiveness of visualising the issue through animation can be better in form of moving visual therapy to most of the people (Mason, 2011). Animation can make people feel less pressure because it has the power to inspire and telling people about the issue arise.

\subsection{Case study regarding mental illness in animation}

\subsubsection{Out of Bounds by Viktoria Piechowitz (2014)}

The story is about the character named Allan's Asperger who having an OCD (Obsessive Compulsive Disorder) or agoraphobia in boundaries that challenged when he needs to go outside to save his only pet friend named Paul (Out of Bounds, 2014).

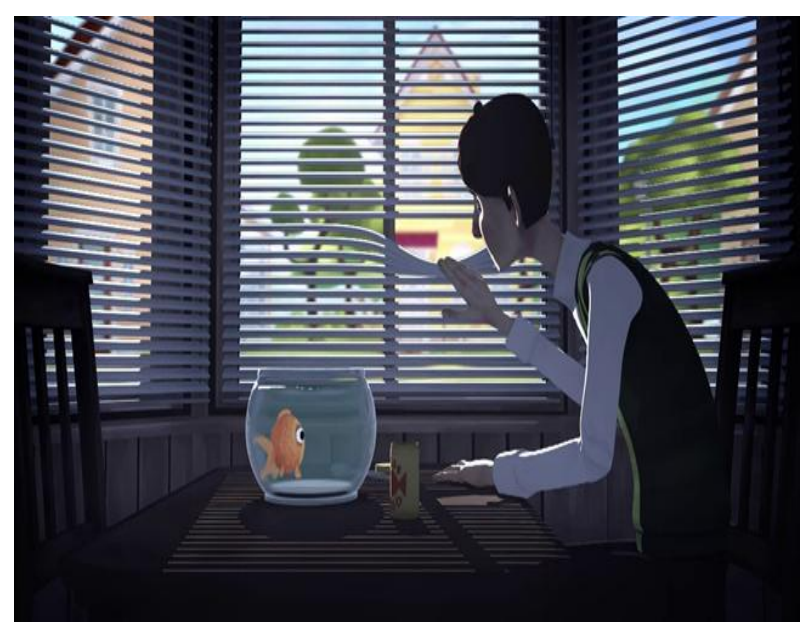

Figure 2.1 Out of Bound (2014) scene

Figure 2.1 showed that the character who always look outside the window in his own house that he is afraid to go out because his mind always thinking about the consequences that might happened to him if he ever to go outside.

\subsubsection{Dream Catchers by Gabriel Freire (2014)}

The short animation titled Dream Catchers is a short 3D animation was created by Gabriel Freire. The story is about a girl named Alice is having some reoccurring nightmareproblems. She only thinks a dreamcatchers will stop her nightmares (Dream Catchers, 2014).

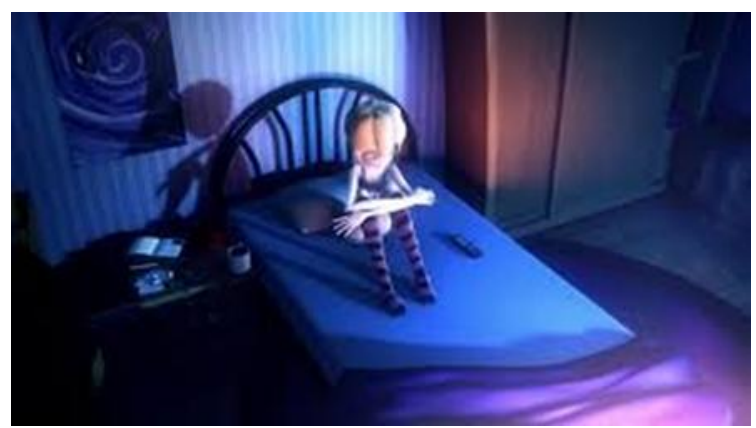

Figure 2.2 Scene when the character having a nightmare in Dream Catchers (2014)

\subsubsection{Caldera by Evan Viera (2012)}

The synopsis is about, Caldera, a young girl who goes off her medication and leaves a bleak metropolis to immerse herself in a vibrant oceanic cove. The story is about the young girl's impossible predicament, where she cannot live in both the fantasy and haunting world of psychosis or in the marginalizing society that mandates her medication (see Figure 2.3).

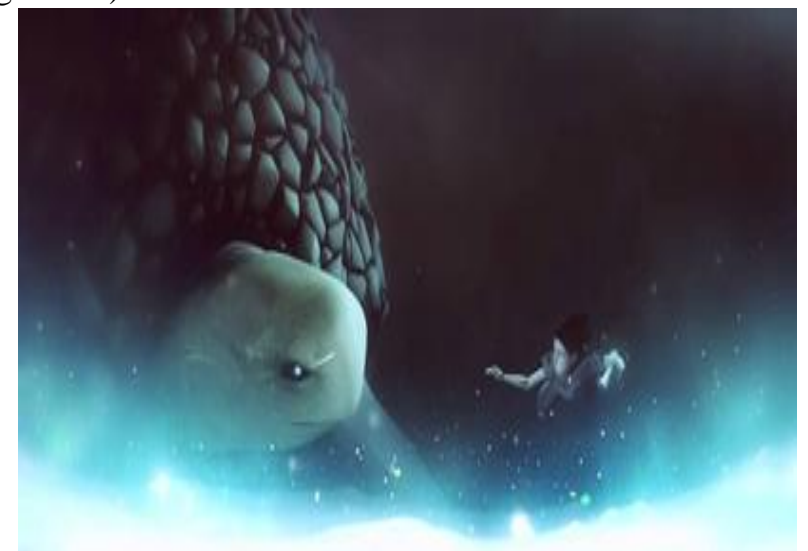

Figure 2.3 Caldera (2012) scene

Based on Evan Viera writes in his website, he stated that CALDERA is inspired by his father's struggle with schizoaffective disorder. In states of delusion, his father has danced on the rings of Saturn, spoken with angels and fled from his demons. His father has lived both in a fantastical and haunting life but one that is invisible to the most of them. In their differing of understanding the reality, he blindly mandates his medication, assimilate his father to their marginalizing culture and entirely misinterpret his father for all his worth. CALDERA aims not only to venerate his father but these brilliant minds forged in the haunted depths of psychosis (Evan Viera, 2012).

When viewing the film on YouTube, we have discovered the statement of Evan Viera's statement about his father. The creator wants us to be aware about the mental illness's vision. For the reason of the observations, the animation makes the effort to tell the experience from the effects showed in vary images to catch the audience sight in this mental illness topic.

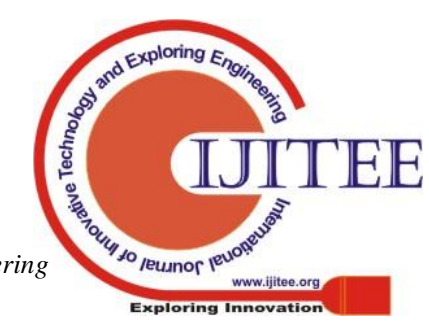




\subsubsection{Inside Out by Pixar (2015)}

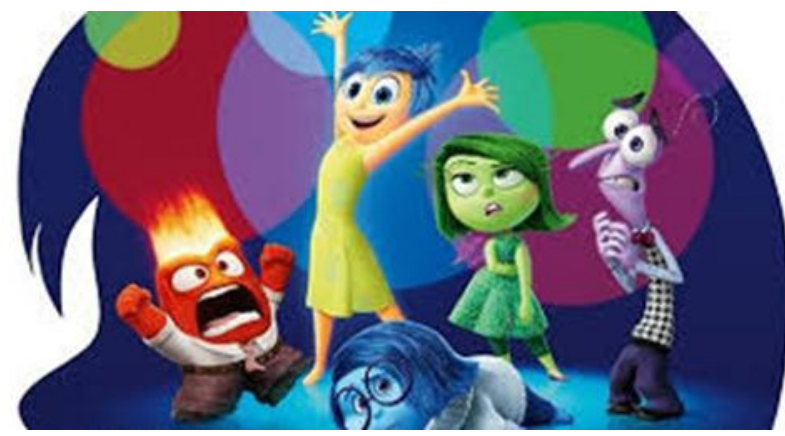

Figure 2.4 Inside Out (2015) poster

The story was released by Disney and made by Pixar in 2015. This animation story is about Riley, a young girl whose world is turned upside-down when her family decided to moves in San Francisco. They were living in Francisco. The story is told through Riley's emotion characters which is Joy, Sadness, Anger, Fear and Disgust (Kimberly Sena Moore, 2015). They follows her transition into new place from a happy life into a stressful life. It shows about development of Riley childhood to a preteenager but almost turned Riley into depression.

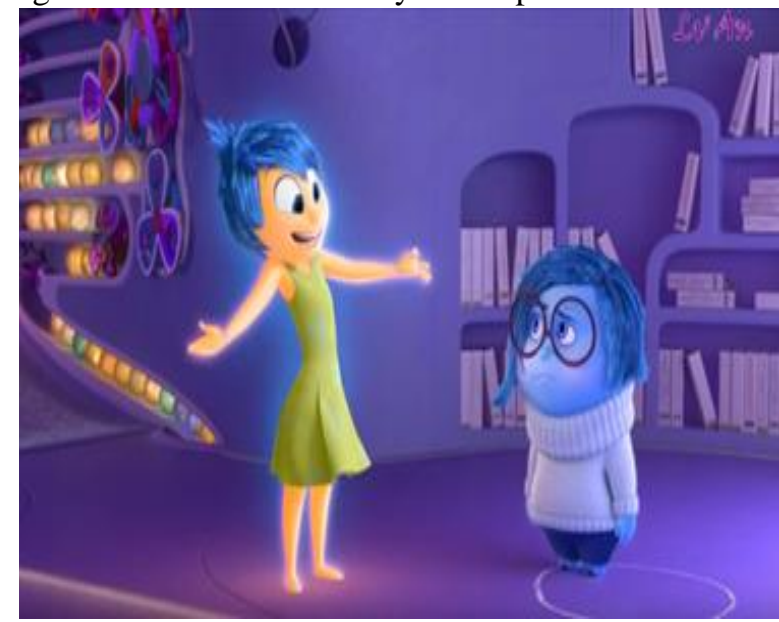

Figure 2.5 Inside Out (2015) scene showed Joy and Sadness trying to cope with Riley's new life

\subsection{Case study regarding mental illness in animators}

\subsubsection{Paul Boyd}

According to Wikipedia, Paul Boyd was an Americanborn Canadian Animator. He was a member production team for the Cartoon Network creating the television series animation, Ed, Edd n' Eddy as a title sequence of animator and also director. He showed an unusual gift for the expressions in visual arts for 15 years, he had a successful career as an animator, employed by a number of different animation studios in Vancouver. Minnesota in idyllic life but turned into stressful life in San

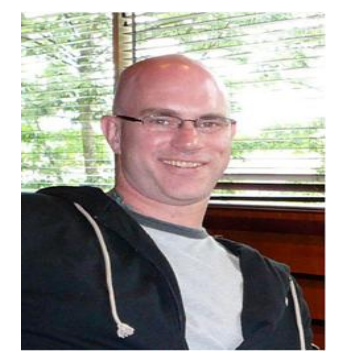

Figure 2.6 Photo of Paul Boyd

Figure 2.6 showed that he was the example that the animator Paul Boyd who was living in the mental illness. He being diagnosed that he had bipolar disorder or being called with manic depression and he lived with the illness for almost 20 years. He used to receive the constant and effective treatment before he died. Most of the time, he was well and there's few guessed that he suffered from any kind of mental disorder but he would suffer in mania and depression that could made him delusions and made him fear in imagined threats.

The article said, he bravely climbed back in the depths of his illness and able to work and enjoyed his life. The media statement of Paul Boyd's family been found in the article of Amid Amidi posted in Cartoon Brew website, on 8th August 2007 that said, he was a big and strong man whose appearance to intimidate for those who did not know him. He was gentle and kind. His actions during his last moments on earth were not part of his personality but were a result of the irrational fear produced by his own illness. Paul loved his family dearly and was loved by all who knew him well. Based on the article regarding Paul Boyd illness, he was a strong animator to appreciate what kind of courage it took in his life until he became worsen.

\subsubsection{Signe Baumane}

Signe Baumane is the famous animator for her works on Rocks in My Pockets. Based on the research and data through the Wikipedia, she is a Latvian animator, fine artist, illustrator and also a writer. She currently living and working in New York City and she is a member of the Academy of Motion Picture Arts and Sciences. Moreover, she also a teacher and taught animation at the Pratt Institute from year 2000 to 2002 .

Signe Baumane is the example on animator who suffered in mental illness, which is depression. She received the mental illness from family genetics for generations for many years.

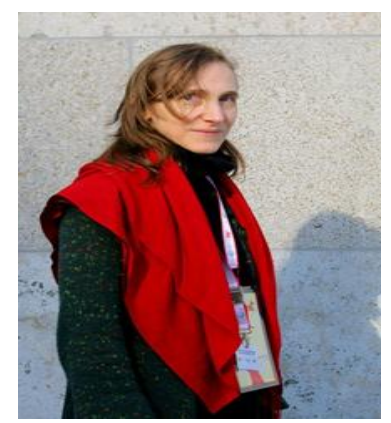

Figure 2.7 Photo of Signe Baumane 
When Signe Baumane been interviewed about the Rocks in My Pockets series animation, the writer stated that Signe Baumane mostly put of her struggles with depression, film financing, gender bias and the challenges of making in her first feature film (Dan Sarto, 2015).

\subsection{Conclusion}

In conclusion of the research and based on the case study above, mental health issue is a difficult subject to talk for both who suffered and those who care about sufferer (Kim Emson, 2017). It can be difficult to understand if someone who not suffered in mental illness. So the scope to visualize animation is the only way to increase the awareness regarding mental health issue among people. It maybe would not have worked as effectively in live action but can be cover in animation to abstract the complex of the subject.

\section{RESEARCH METHODOLOGY \& RESULTS}

\subsection{Introduction}

The chapter will tell the methodological framework and the method of analysis that presents the texts description based on the title. This section will consist the study of colours that being used in animation regarding mental health issue and also the body movement that will shows in animation regarding mental health issue.

\subsection{Colours in Psychology Area}

Colour is a concept that philosophers, artists and scientists that have historically spent a great deal of time exploring and quantifying (Kaitlin L. Brunick \& James, 2013). According to Wikipedia the colour psychology is the study of hues as a determinant of human behaviour. Colour can influence the perception that not obvious which is the taste of food. Colour can influence a person and it is important to remember that it effects different between people. The colour psychology been used in marketing and branding but also been used in visualising animation. Some studies find colour can affect mood of a person. But it is not precise that colour can bring the mood and emotion to the person.

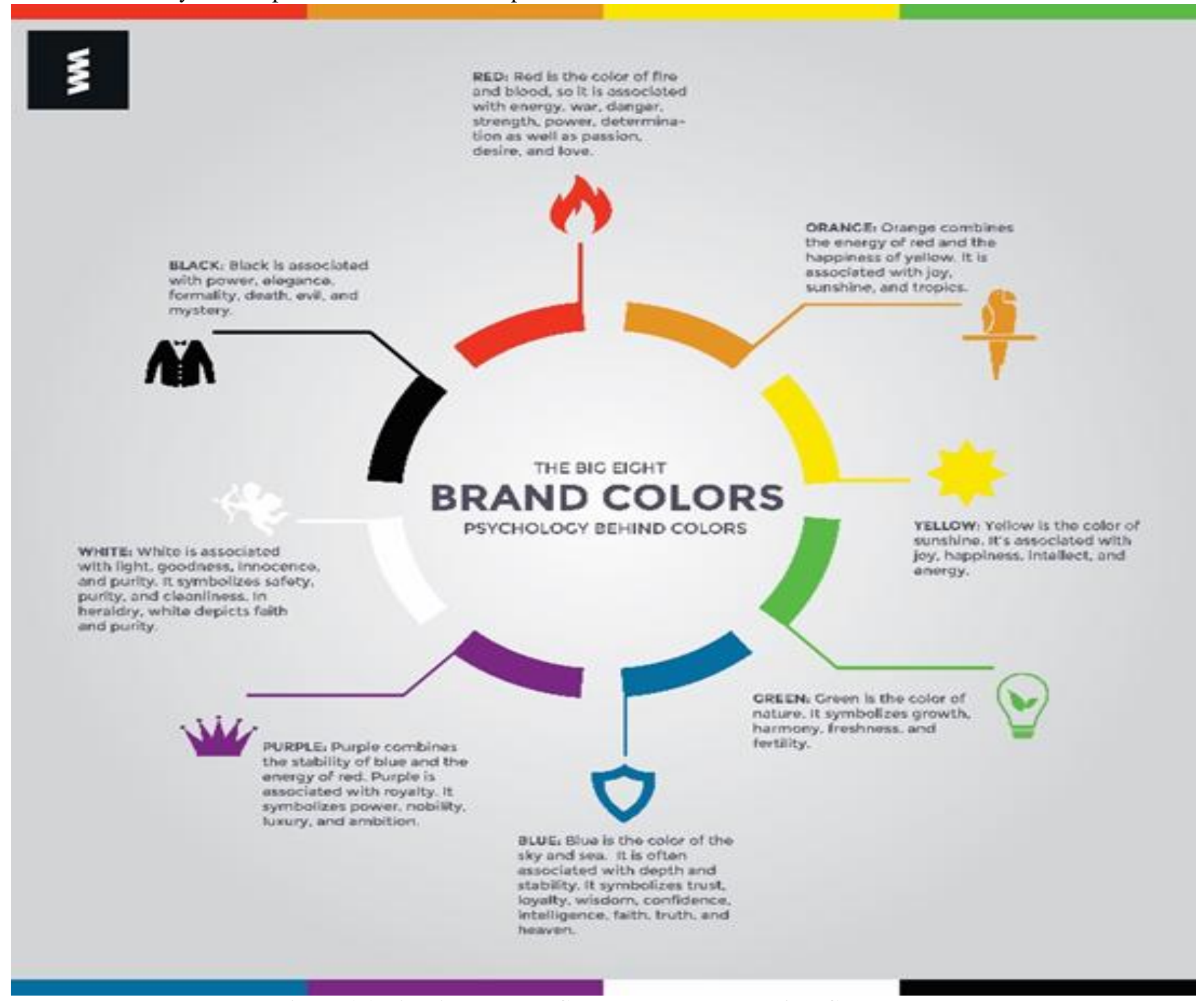

Figure 3.2 Big Eight Brand Colour Psychology behind Colours

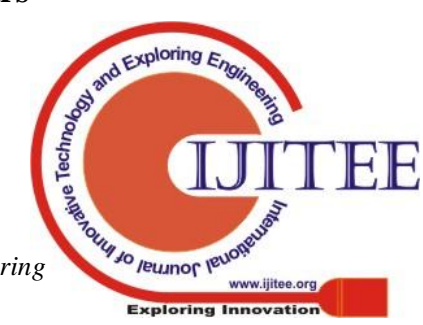


The figure model 3.1 is based from Josheds article (2015). The image model shows the meaning of the commonly associated of the 8 most of commonly used colours in marketing and branding strategy, which is red, orange, yellow, green, blue, purple, white and black. Basically, the model of colour used also based on the colour wheels original model.

The model research showed a detail of colours of emotion, starts with red is the colour of fire and blood and it is filled with energy, war, danger, strength, power and also determination as well with the passion of desire and love. Orange is the combination of red and yellow colour. It showed a joy, sunshine and tropics emotion. Next is yellow colour. It is the colour of sunshine that shows joy, happiness, intellect and energy emotion. Green colour is a nature colour that showed harmony, freshness, growth and fertility of emotion colour. Blue colour is the sky and sea colour, It is used to associate with depth and stability and symbolizes the trust, loyalty, wisdom, faith truth and heaven. Blue colour basically will used in animation for the sad emotion.

Furthermore, the image model also showed the purple colour. It is a colour combines of stability of blue and the energy of red. It showed a colour of royalty that symbolizes the power, nobility, luxury and also the ambition. White is a colour of light and purity. It symbolizes safety, purity and cleanliness. Last one is a black colour. It is a colour of elegance, death evil and also mystery. These eight colours in the model been used in visualising the psychology through the animation.

\subsection{Body Movement and Gesture of Mental Illness} Person

A study confirms that a person's body movements can offer clues into own personality traits and people will find it easier to interact with those who make a move in a certain way. The way body moves may give the impact of own mental health condition (Traci Pedersen, 2016).

Basically, people who having mental illness showed how they usually live their life. The mood and emotion may impact their current self and might be in mental illness. For example, if they have depression, their body movement may looks different and weak and because of their sickness their sorrow may look different from normal people do. There are so many stages and the body movement might vary either in depression or bipolar disease as well as schizophrenia disease see example in figure 3.2 illustrate by Hugo Lin (2018).

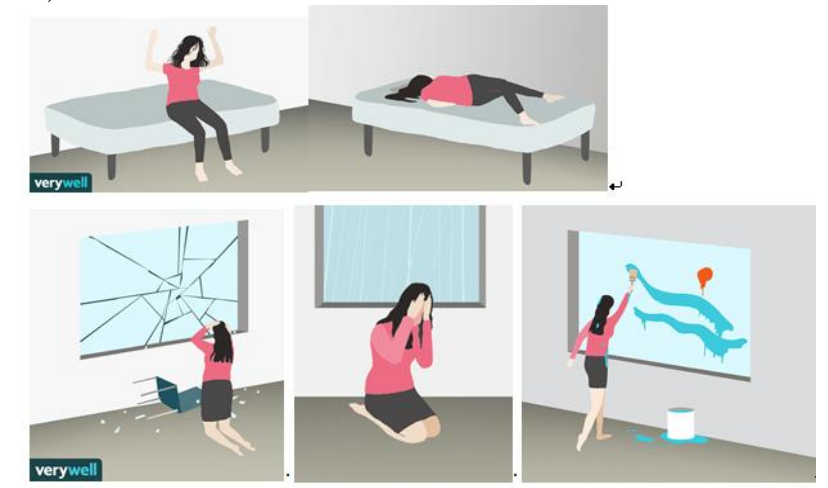

Figure 3.3 Example of mental disorder people in their movement
According to psychiatrists organization American Psychiatric Association (APA) stated that some movement disorders also qualify as mental disorders based to their psychological impact that traditionally viewed as mental health problems.

The movement disorders also make someone having a mental disorder symptoms. Doctors refer how the movement disorders are not faked and will identifying physical cause as a psychogenic movement disorders (Laura Nott, 2018). Examples might be in conditions include parkinsonism which is someone who having disease that refers to dysfunction and cell death of the portion of that brain that produce some chemical that transmits signals between brain and nerve cells (Rachel Nall, 2018).

\subsection{Colours in Visualising Mental Health in Animation}

According the article, Colouring the Animated World by Kaitlin L. Brunick and James E. Cutting in 2014 stated, the revolution in computer animation began with the first fully computer-based animated film, Toy Story (1995). From two-dimensional animation into three-dimensional are digitally constructed in environment filmmaker in constructing visual narratives. Colouring in a 3D environment and set of the characters may involves great deal of initial time and also the planning the ultimate outcome in a greater degree of colourization. Colours play roles in animation to send the message for those who watch either adult or children. The control of colour in the setting shows the artistic value in particular psychological responses from the viewers.

The use of colour in animation film is important and can used to convey the messages and information. With the scenes of colour schemes in Pixar animation films can turned abundantly clear that they absolutely know to work with the palettes. A real-life shot can be framing and can control in a lot of aspects of it such as in set design, lighting, blocking of the characters within it. The use of proper colour palette in a movie is lot more vital. Pixar is able to create the use of colour as supporting character in each movie that is capable on relaying the feels in scene than a normal traditional film able to show (Blake Rodgers, 2015).

Furthermore, in article of Blake Rodgers in 2015 also stated, how proper colour of palette in a movie used that will make the impact towards the mood and environment of the messages of certain storyline that we realize. A striking contrast of colour in the main characters which further allows to pay attention for what filmmakers intended. For example, a dangerous sequence like the jellyfish scene in the Finding Nemo (2003) that make Marlin and Dory as the only contrasting colours of the characters in an jellyfish field of pink so that the characters can react and capture the eye of viewers (see figure 3.4a). 


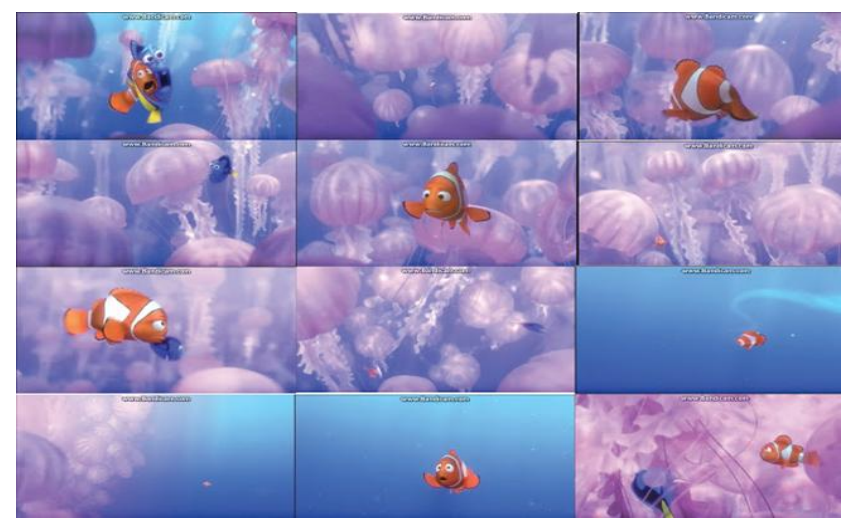

Figure 3.4a Jellyfish scene in Finding Nemo (2003)

Next example is from The Incredibles (2004) animation scene when Dash the son of Mr. Incredible been chasing by the villain in the green jungle that showed how the character colour pop up and can impact the mood in the scene (see figure 3.4b). The colour of villain in the scene used was grey and it showed he is a supporting character apart of colour of Dash they used that can make Dash pop up in the scene.

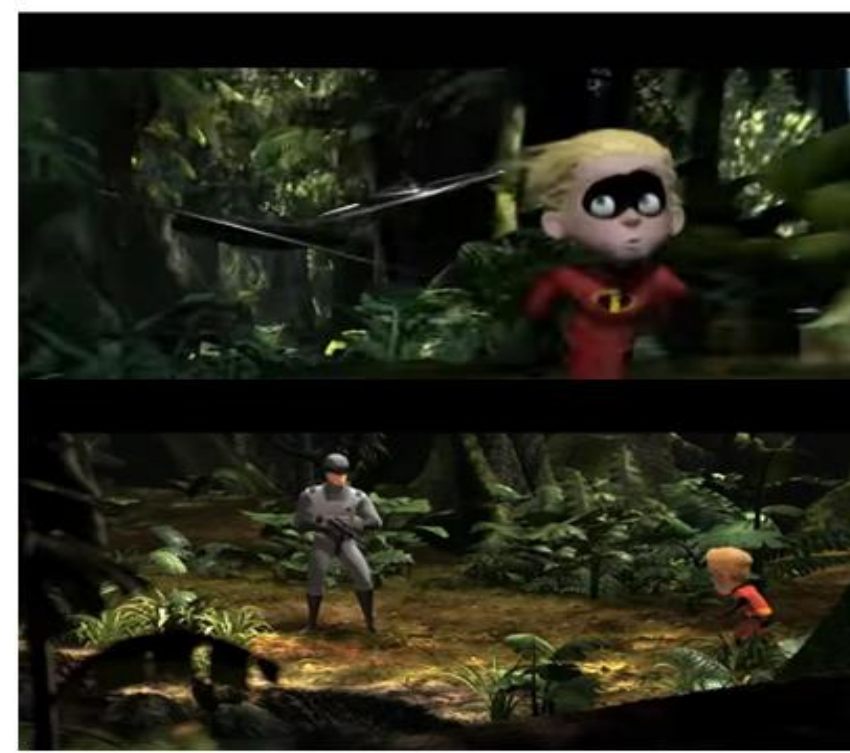

Figure 3.4b Dash scene when he faced the villain in the jungle in The Incredible (2004)

\subsubsection{Pixar animation visualising mental health based on colours}

\subsubsection{Inside Out (2015) by Pixar}

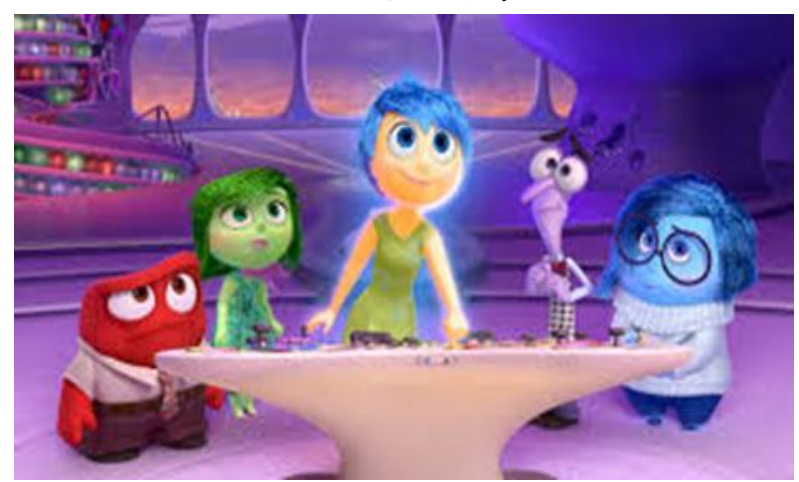

Figure 3.4c Scene of Riley's emotion Joy try to control the stability out of her life in Inside Out (2015)
Pixar released animation movie Inside Out in 2015 about a mental health. In this animation, Inside Out's plot centres on emotions that play with psychological issues. Pixar showed about primary emotions and episodic memory that directly with the storyline. The characters involved with the colours of emotions that play in a girl character's head. Riley character teaches the important lessons how to cope with stress and changing emotions. (Becky Fraynt, 2018).

The characters of a girl emotion showed Joy which is a yellow colour that showed happiness of Riley's life, Sadness is a blue colour that showed sorrow of Riley's emotion, Anger is a red colour character that showed angry and mad of Riley's emotion, Fear is colour purple colour that showed of Riley's biggest fear emotion, Disgust is in green colour that showed Riley's disgust emotion towards something.

Based on this movie, Pixar used colour of emotion to show that Riley was slipping into depression. Sadness character in this animation shows the confusion about the feelings and actions that will obviously desire to be another way, these are the parts of depression that almost impossible to show in this film. Pixar did manage to convey a very simple and perfect animation to show a person that went through in mental illness. (Kayleigh Roberts, 2015).

\subsection{Body Movement and Gesture in Animation}

Body movement or gesture is very important roles in making animation. According to The Silent Protagonist Team in 2016 WordPress, it stated the importance of the aspect of the acting or the animation can also be traced in the media origin in the acting theatre. Actors had the ability to show the emotion portray the messages to the audience. With the body language used in theatre, can make the audience feels and understand the emotion of the scene. Example, an actor will show the posture of deep slumping of the shoulders to show the sadness of itself. Acting for the animation really play big roles in making the animated character. Based on the acting in the theatre shows how animation can make the animated character feels alive.

"Creating an animated character that's believable is a big challenge"

Stated Antony Ward, a creative director and also an animator regarding a body movement in animation. Body movement play roles in making animation films because it can visualising the animation and can show the emotion of the characters based on the research title.

Antony Ward also the tips in the Rob Redman article in 2018. He stated how to make the animated characters to convey the message through the story firstly to observe reallife characters of normal person and mental illness person. With the help of real life characters in acting can help making cartoon characters feels alive. Then he stated to study the psychology of the movement and also search for the references. Based on the emotion of the situation in the story, study how the mental effects the emotion of the character is a must for example how happy person and sad person convey the message through their emotion with their gesture (Rob Redman, 2018).
Blue Eyes Intelligence Engineering \& Sciences Publication 
Based on the movement of the animated character, it also include with the emotion or expressions of the character itself. According to article by Eric Wargo in 2005, there had been a Convention in Los Angeles called a discussion between a director of Pixar Animation Studios, Pete Docter about the expression on the character. Pete Docter stated that his team in Pixar Studio of digital artists heavily work of Ekman and also the other psychologists on research goes about the expressions of emotion and they started using the Facial Action Coding System that Ekman and a colleague devised in 1970s to studying about facial muscle movement. They started to study for the character in the animation they made based on the character movements to the facial expressions in certain situation based on the story of the film.

In the APS Annual Convention in Los Angeles, Pete Docter also showed how he and other animators constructed the movement and the expressions for Monsters Inc. characters and studying how many eyes involved in the animation (Eric Wargo, 2005).

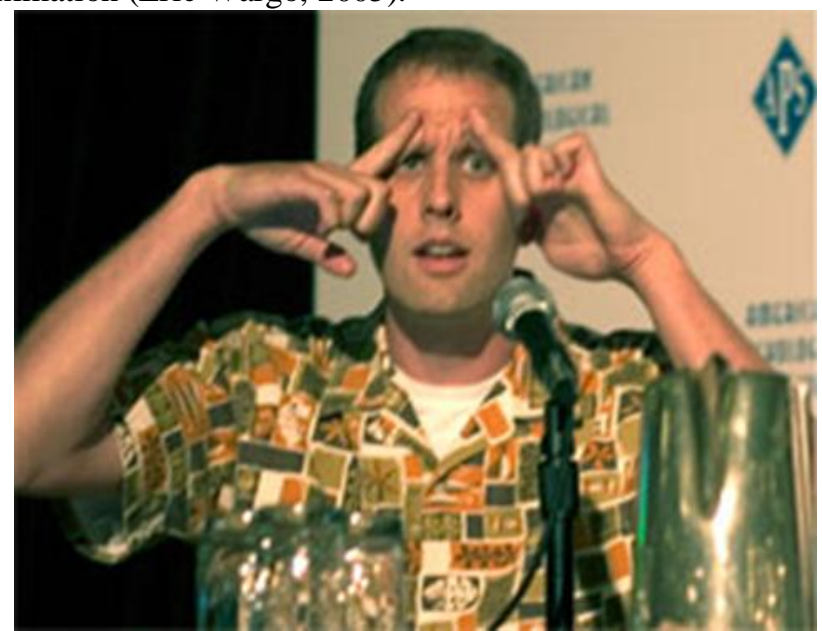

Figure 3.5a Pete Docter showed how he studied the movement of facial expressions during APS Annual Convention in 2005

3.5.1 Pixar animation visualising mental health based in characters

3.5.1.1 Riley in Inside Out (2015)

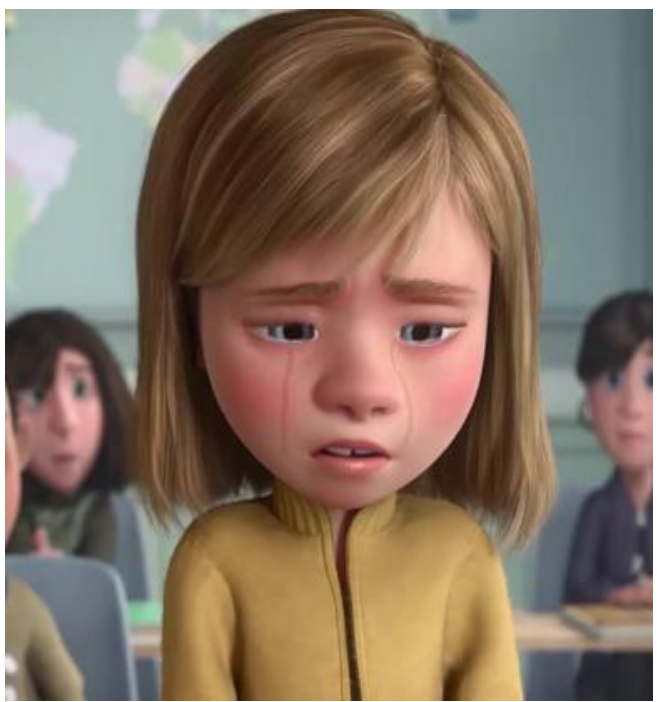

Figure 3.5b Scene when Riley tells her life story in class in Inside Out, 2015 by Pixar
In this animation, it shows that Riley a young girl struggling with her new life and it personified her four key of emotions (Lucinda Everett, 2018). It is concluded that it's actually totally fine to feel sad and something that any child struggling with depression that will find deeply reassuring.

The story plot plays with emotions and coping with the psychological issues. Pixar plays with primary emotions with lots of main memories through Riley's head.

Many of Riley's problems make Joy her happy emotion trying to get rid of Sadness a sad emotion to achieve Riley's goal (see figure $3.5 \mathrm{c}$ ).

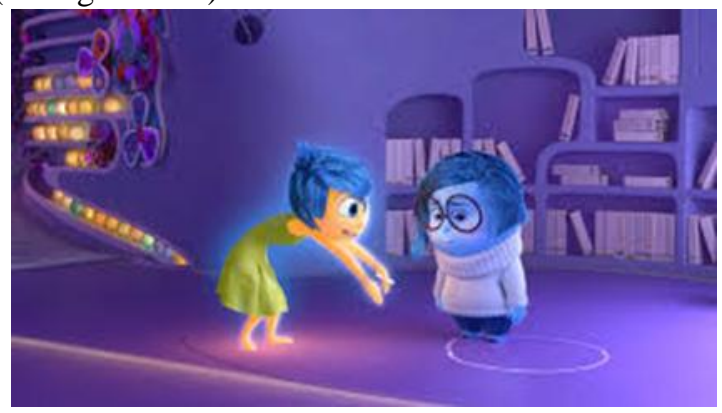

Figure 3.5c Joy trying to make Sadness stay in the circle

The key is for people to find out that how the person feels when they encounter into the mental illness (Becky Fraynt, 2018). All those unpleasant mixed emotions occurred in the stressful life. This research states that people that can accept the unpleasant emotions are actually more likely into depression.

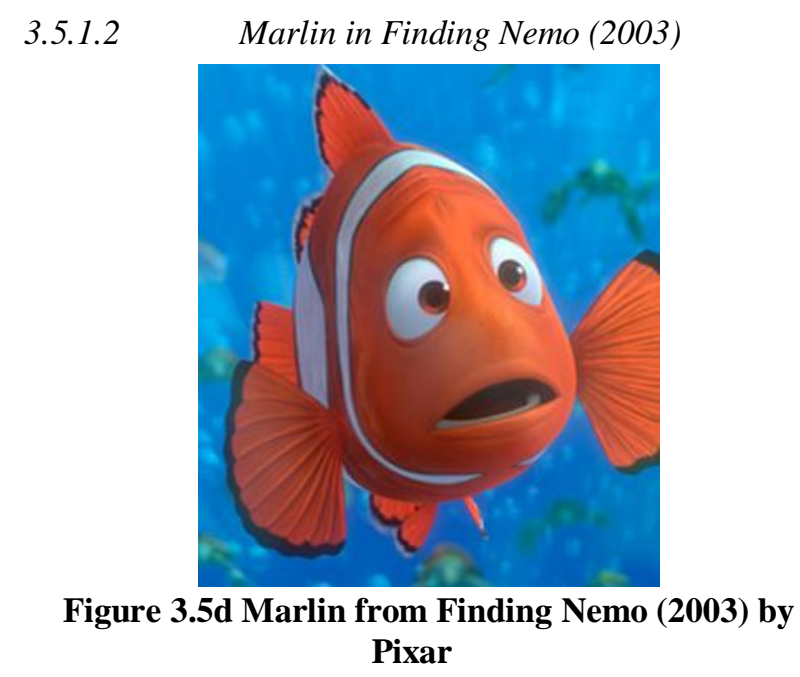

Finding Nemo is a story about father's heroic journey across an ocean to rescue his son. The character named Marlin is Nemo's father is having an anxiety disorder. (Becky Fraynt, 2018). Based on the study by watching the animation, Marlin is suspected to have anxiety because of his traumatized past, when his wife was killed by a barracuda while his wife trying to protect their eggs but only one egg left which is Nemo (see figure 3.5e). 

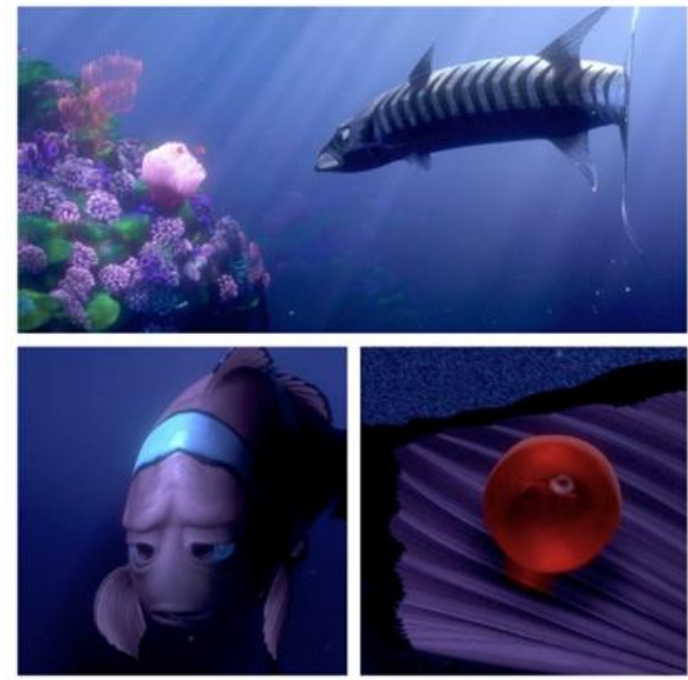

Figure 3.5e Scene when Barracuda eat Marlin's wife and left only one egg in Finding Nemo (2003)

The past has haunted Marlin for many years and it makes Marlin to become over-protective father to Nemo. He always protected Nemo to go to school because letting Nemo go always make him thinking all those bad things that will happened. When Nemo is kidnapped by scuba driver (see figure 3.5f).

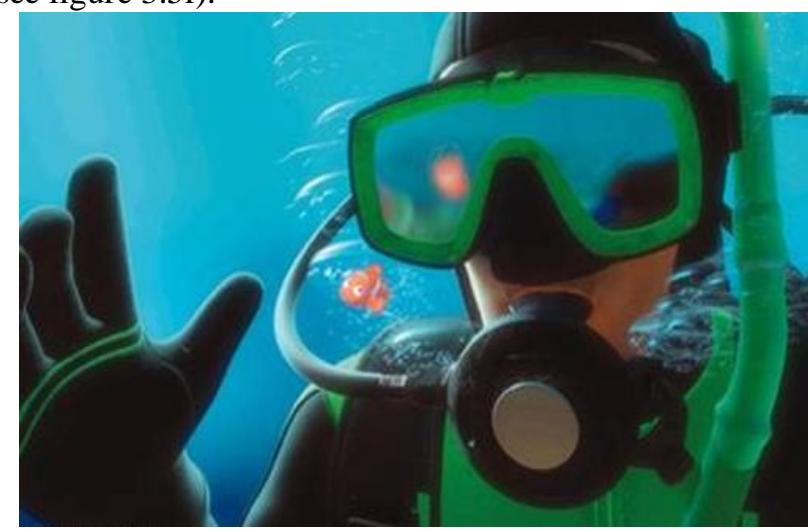

Figure 3.5f Scene when Nemo being kidnapped by scuba driver in Finding Nemo (2003)

Marlin needs to face his fears and he always overthinking for what happened and trying so hard to save his son. He almost lose his fate when he trying to save his son. He overacts over the situation because he too worried (see figure $3.5 \mathrm{~g}$ ).

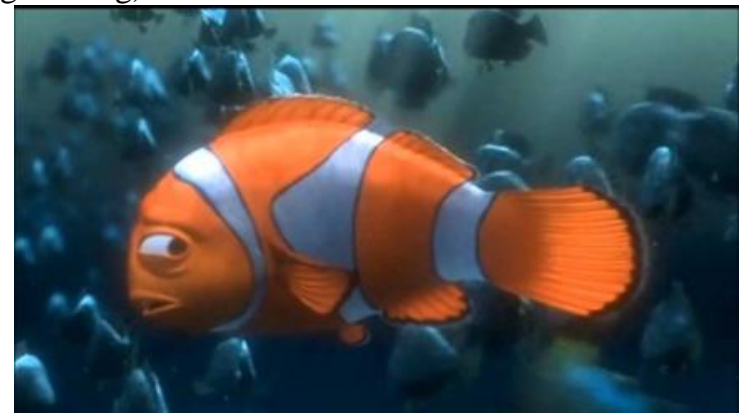

Figure 3.5g Scene when Marlin trying to give up finding his son in Finding Nemo (2003)

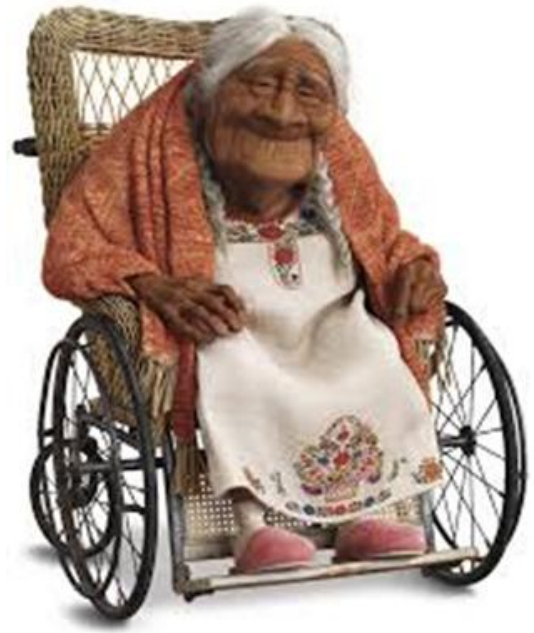

Figure 3.5h Mama Coco in her chair in Coco (2017) by Pixar

This is the character in Coco called Mama Coco by her family. According to Fandom Movies Community website, her name is Coco Rivera and she is a great-grandmother of Miguel. The character showed in the movie that she has dementia. Dementia is a personality changes by the person and have difficulty by remembering important events or people. Mama Coco not even talking at the start in the movie and she seems too slow in her movement and not remember anything around her. She not even talking and just stay in her position that is why we see that Mama Coco seems to have this mental illness in her late 70s. In this film, we also can see how Miguel really closed with his greatgrandmother, Mama Coco and how he tried to talk with her every day.

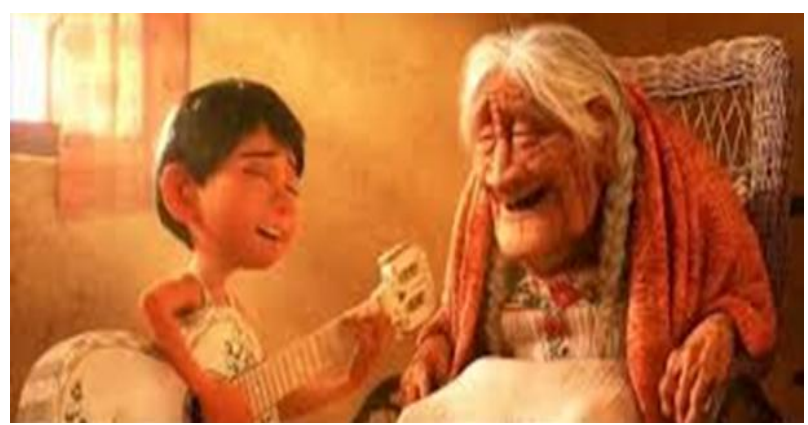

Figure 3.5i Scene when Mama Coco and Miguel sing together

Miguel did an excellent job in way to connect their family and with someone with dementia (Becky Fraynt, 2018). We can see how Miguel bonds with Mama Coco when he sang Mama Coco's late father (see figure 3.5i), Hector song that make Mama Coco remembered his father back before she died. Mental health issue really make us feel touch in lives. Stories in films can make us to begin talk and open the conversation about the mental health issue.

\subsubsection{Mama Coco in Coco (2017)}



Mike Wazowski in Monsters Inc. (2001)

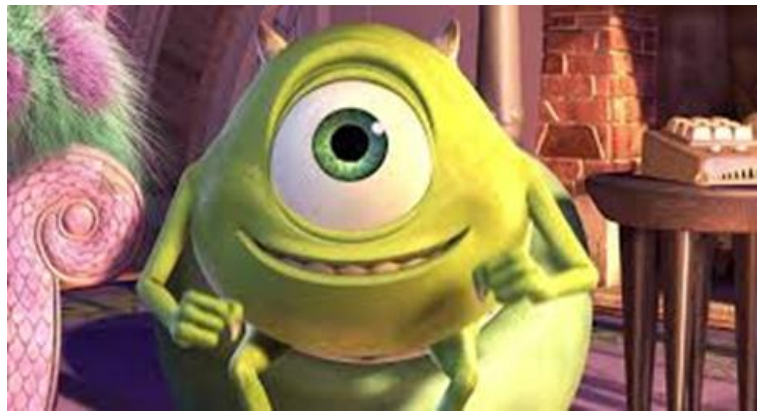

Figure 3.5j Mike Wazowski in Monsters Inc

In this animation Monsters Inc. Mike Wazowski is obviously diagnosed with ADHD. It is a mental disease called Attention Deficit Hyperactivity Disorder (ADHD) that usually affects children and teens. Those with ADHD may be hyperactive and unable to control the impulses and may having trouble to pay attention ().

The character, Mike Wazowski attempt to diagnosed with ADHD whenever Sully his best friend get into trouble. Mike usually yelling and hyper in the scene when he needs to make the kid scared (see figure 3.5k).
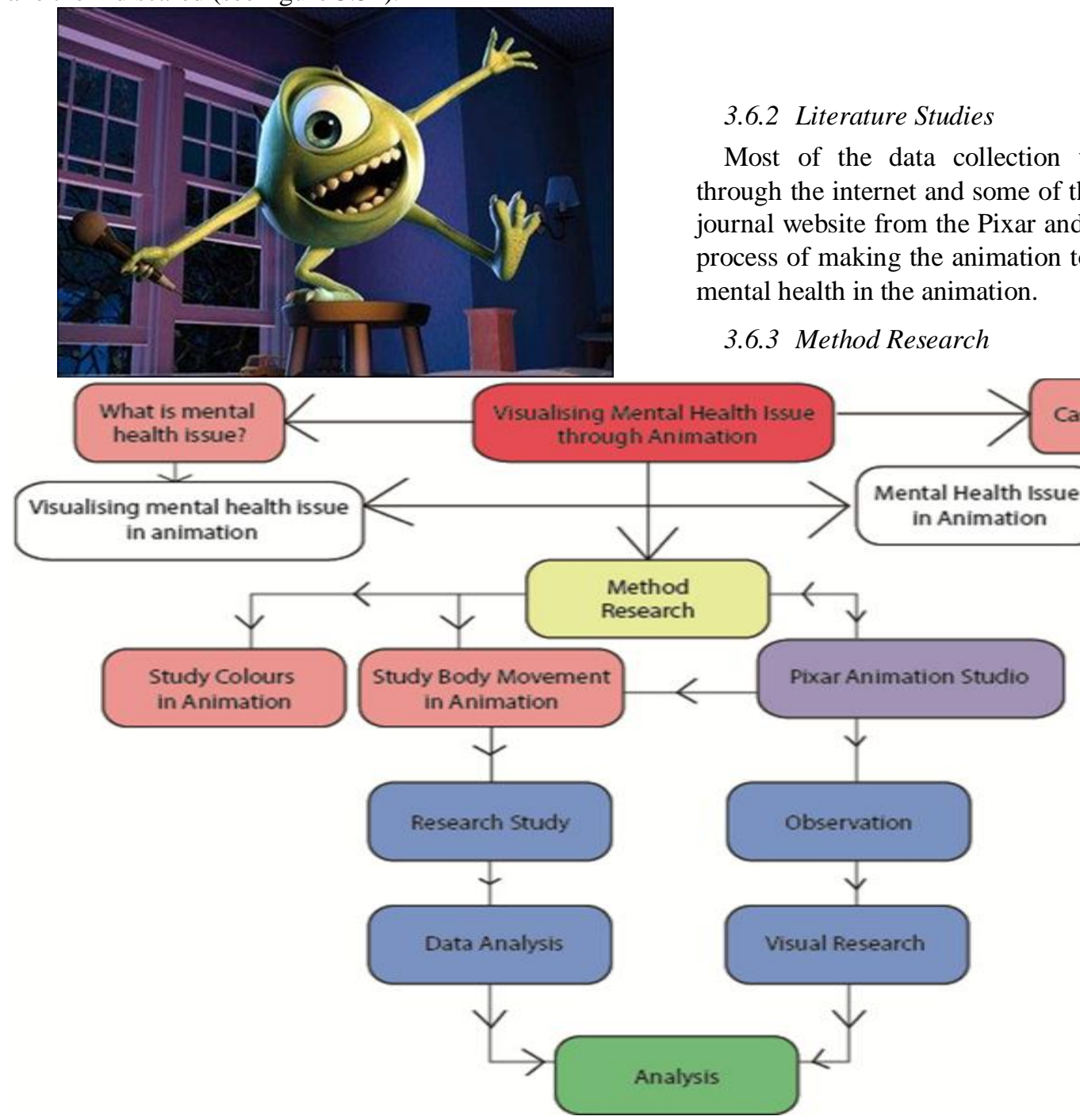

Figure 3.6 Post Method Research Model

\section{Figure 3.5k Scene when Mike goes to children room to scare them}

The symptom was said he having the hyperactivity because he always screams, yells, dances around, sometimes, words flow out of his mouth like word vomit. Next symptoms was said when he is impulsive. The scene showed when Mike clearly portrays every time he tries to help Sully out of a bad situation. He never thinks over anything first and usually the situation getting worst. (Lindsay Smith, 2013)

\subsection{Data Collection}

\subsubsection{Observation}

This research study is made by watching the animation film based on mental health issues. Many of animation short films and movies been made these days to send the message about mental health issue to spread the awareness towards people. This research was found when the animators tried to visualize it into colours and the body movement showed in the characters in certain animation regarding of mental health issues.

\subsubsection{Literature Studies}

Most of the data collection was made by searching through the internet and some of them were taking from the journal website from the Pixar and Disney studios about the process of making the animation to send the message of the mental health in the animation.

\subsubsection{Method Research}

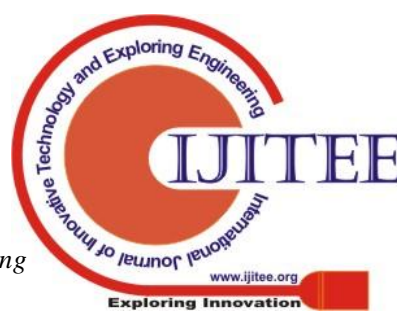


Based on Figure 3.6, there are stages to complete the research of study in visualising mental health through animation basically will be focus on the 3D animation and characters. This research will focus on the background study about mental health issue that rises among animators and through animation short film then how the messages in the animation convey about mental health issue. The examples are based on the chapter 2 that convey the messages of types of mental illness that been search by watching certain animation. This model is related on how this research study been made from earlier chapter from studying mental health issue that arise until focusing on the certain animation studio which is Pixar Animation Studio that have the animation regarding the mental illness. By watching and visualing the animation and the colours of the animation they made, we see that Pixar can make the colour mood changed and made viewers realized how the messages sent through the animation itself. In animated characters of animation also convey the message regarding mental illness that we can see through the gesture and emotion of the characters. Therefore, there are so many things need to focus on portraying the messages to the viewers so that the issue can be talked more to spread the awareness through animation.

As a result of the study, the main stages will be focus on the main aspect of the mental health and mental illness that arise these days and how to spread the awareness with it. The materials were collected from the article journals, research papers from internet such as Wikipedia, Blogged, Google and videos of the films of 3D animation. The research been made to study related to title was from taking resources about the colours and body movement thesis until watching various animation from selected studio which is Pixar to study and observing how Pixar Animation Studio successfully made the animation that can open many viewers' eyes until now regarding mental health issue. After collecting the data, literature studies were made from online research study or visual studies. Through collecting the data from the internet, the researchers can make the comparison with many types of animation that convey the animation regarding the title either in stop motion or 2D animation. But this study only focuses on the 3D animation scope because there's still need to increase the animation made with $3 \mathrm{D}$ these days to cover the issue.

The method of observation was made by watching many 3D animated films to see how the characters moved that showed the sign of mental illness symptoms to make it more clear in the study. The colours of the animation also been study in animation to see how the colours changes that been made to impact the mood of the viewers. From this, we can get more information to prove the research study based on the colours and the gesture in 3D animation that been made by Pixar. Finally the data analysis method can increase the study research on making the $3 \mathrm{D}$ animation so that every detail can be more accurate to study regarding the mental health issue that arise and can be understand by the viewers and also the readers.

\section{CONCLUSION}

In this study research was made in due to these days issue which is mental health issue. By study the research about the mental health issue based on the animation been made either in short animation until made into film animation, we know how to display the sources by the elements in the animation. What has been study was about the animation that has the messages regarding mental health issue and also the animators who have mental illness. Some of the animators we know are having and living in mental illness and some of them expressing their life in the animation. For what we study, the animation conveys the message through the colouring, mood and also the gesture movement of the characters in the animation. Thus, most of the study in the research method is taking by observing and research from Pixar studio animation.

\section{REFERENCES}

1. Almeida, E. (2015). How Animation Is Starting A New Conversation On Mental Illness. toddysseyonline.

2. Amidi, A. (2007, 20 8). More about the death of Paul Boyd. Cartoon Brew.

3. Animator, B. (1970, January 1). My Medicated Cartoon Life. Retrieved August 10, 2018, from mymedicatedlife: http://mymedicatedlife.blogspot.com/

4. Baumane, S. (2014, September 3). Signe Baumane Boldly Animates Family Depression in 'Rocks in My Pockets'. (M. Silverstein, Interviewer)

5. Caldera, A Beautifully Surreal Animated Film About Mental Illness. (2013, April 10). Retrieved August 10 2018, from Laughing Squid: https://laughingsquid.com/caldera-a-beautifully-surrealanimated-film-about-mental-illness/

6. Everett, L. (2018, January 25). Morbid? No - Coco is the Latest Children's Film with a Crucial Life Lesson. The Guardian.

7. Fandom. (2018). Pixar Wiki | Coco Rivera. Retrieved from Fandom: http://pixar.wikia.com/wiki/Coco_Rivera

8. Fraynt, B. (2018, July 7). 4 Pixar Movies That Can Start a Conversation About Mental Health. Retrieved from Fandom: http://fandom.wikia.com/articles/4-pixarmovies-that-can-start-a-conversation-about-mentalhealth

9. Healy, J. P. (2016, June 6). Color in "Inside Out" - How Color is used in the film. Odyssey.

10. josheds. (2015, April 10). RESEARCH | COLOUR. Retrieved from JOSH.EDS | VIS.COMM: https://josheds.wordpress.com/2015/04/10/researchcolour/

11. Mental health facts and statistics. (2017, April). Retrieved August 17, 2018, from Mind for better mental health: https://www.mind.org.uk/informationsupport/types-of-mental-health-problems/statistics-andfacts-about-mental-health/how-common-are-mentalhealth-problems/\#.W3aOIs4zapp

12. Miclau, K. (September 11, 2017). De-stigmatizing Mental Illness Early: Role of Childhood Animations. SMHR - Students in Mental Health Research.

13. Moore, K. S. (2015). 5 Difficult Concepts Made Easier by Disney's "Inside Out". Psychology Today.

14. Nall, R. (2018, January 12). What is Parkinsonism? Medical News Today.

15. Nott, L. (2013, September 18). Overlapping Effects of Mental Disorders and Movement Disorders. Elements Behavioral Health. 
16. Paul_Boyd_Animator. (n.d.). Retrieved August 17, 2018, from Wikipedia: https://en.wikipedia.org/wiki/Paul_Boyd_(animator)

17. Pedersen, T. (2016, October 9). Body Movements May Give Clues To Personality, Mental Health. Psych Central.

18. Rapold, N. (2014). Depression, a Persistent Demon, Stalks One Family for Generations. The New York Times, C6.

19. Redman, R. (2018, January 19). 15 ways to improve your character animation. Retrieved from Creative Bloq: https://www.creativebloq.com/audiovisual/improvecharacter-animation-41411447

20. Roberts, K. (2015, June 19). Why 'Inside Out' will start an important conversation about mental health. Hello Giggles.

21. Rodgers, B. (2015, June 21). Pixar's Use of Color is Incredible. Nerdist.

22. Sami. (2016, February 9). Finding Nemo Communicating using non-human characters with human/animal stereotypes. Retrieved from Research Project

http://samitaylorad6000.blogspot.com/2015/11/findingnemo.html

23. Signe Baumane. (n.d.). Retrieved August 15, 2018, from Wikipedia:

https://en.wikipedia.org/wiki/Signe_Baumane

24. Smith, L. (2013, December 20). Psychological Disorder Characters - Mike from Monsters Inc. Retrieved from Preze: https://prezi.com/hquzuegvz5um/psychologicaldisorder-characters/

25. Studio, P., \& Docter, P. (Directors). (2001). Monsters Inc. [Motion Picture].

26. Studio, P., \& Docter, P. (Directors). (2015). Inside Out [Motion Picture]

27. Studio, P., \& Unkrich, L. E. (Directors). (2017). Coco [Motion Picture].

28. Studio, P., Unkrich, L. E., \& Stanton, A. (Directors). (2003). Finding Nemo [Motion Picture].

29. Team, T. S. (2016, April 10). Body Language and Its Use in Animation. Retrieved from The Silent Protagonist - "Silence speaks louder than words.": https://thesilentprotagblog.wordpress.com/2016/04/10/bo dy-language-and-its-use-in-animation/

30. Wargo, E. (2005, 30 8). Animated Expressions. APS Association for Psychological Science.

31. Widdowson, A. (2016, August 12). When The Art Of Animation Meets Mental Illness. (P. Karagianni, Interviewer)

32. Wishart, S. (2018). Why Does Animation Work So Well For Healthcare Stories? Humans Rights News, Views \& Info. 